\title{
PERBANDINGAN ESTIMASI ANGGARAN BIAYA DENGAN METODE SNI DAN BOW PADA PROYEK PEMBANGUNAN GEDUNG D FAKULTAS AGAMA ISLAM UNIVERSITAS ISLAM LAMONGAN
}

\author{
Hammam Rofiqi Agustapraja ${ }^{1}$; Affandi ${ }^{2}$ \\ ${ }^{1}$ Program Studi Teknik Sipil Universitas Islam Lamongan \\ 2 Program Studi Teknik Sipil Universitas Islam Lamongan \\ email : hamamrofiqpsts@unisla.ac.id; affandipsts@unisla.ac.id
}

\begin{abstract}
ABSTRAK
Proses analisa biaya konstruksi adalah suatu untuk mengestimasi biaya langsung yang secara umum digunakan sebagai dasar penawaran. Metode yang digunakan untuk melakukan perbandingan estimasi adalah metode SNI dan metode BOW. Dalam penyusunan harga satuan pekerjaan diperlukan data-data yang mendukung diantaranya gambar rencana, volume pekerjaan, RAB, RKS, daftar harga bahan dan upah tenaga kerja pada daerah penelitian. Dan hasil perhitungan analisa harga satuan pekerjaan yang dilakukan didapatkan perbandingan harga satuan dengan analisa SNI dan BOW. Dari analisa tersebut memperoleh hasil estimasi anggaran biaya yang ekonomis dengan menggunakan metode SNI yaitu sebesar Rp.2.253.760.000,00 sedangkan hasil estimasi anggaran biaya dengan metode BOW yaitu sebesar Rp.2.625.418.000,00. Hal ini karena koefesien dari metode BOW lebih besar dari metode SNI.
\end{abstract}

Kata Kunci : Perbandingan Estimasi, Anggaran Biaya, Proyek, Metode SNI, Metode BOW

\begin{abstract}
Process cost analysis to estimate construction is a direct cost that is generally used as the basis for bidding. The method used to perform comparisons of estimates is the SNI and BOW method. In the preparation of the necessary work unit price data that supports such images to plan, the volume of work, $R A B, R K S$, the list price of materials and labor in the research area. And the result of calculation of unit price analysis conducted found with the unit price comparison analysis SNI and BOW. The analysis of the result obtained from the budget estimate economic costs by using SNI is Rp.2.253.760.000,00 while the estimated budget with BOW method is Rp 2.625.418.000,00. This is because the coefficient of greater BOW method of method SNI.
\end{abstract}

Keywords: Comparison of Estimation, Budget Cost, Project, SNI Method, BOW Method. 


\section{PENDAHULUAN}

\section{Latar Belakang}

Estimasi biaya konstruksi merupakan hal penting dalam dunia industri konstruksi. Ketidak akuratan estimasi dapat memberikan efek negatif pada seluruh proses konstruksi dan semua pihak yang terlibat. Hal yang penting dalam pemilihan metode estimasi biaya awal haruslah akurat, mudah, dan tidak mahal dalam penggunaannya. Estimasi biaya berdasarkan spesifikasi dan gambar kerja yang telah disiapkan owner, jumlah dan luas lantai memperlihatkan karakteristik dan ukuran fisik dari suatu proyek pembangunan gedung. Estimasi biaya konstruksi dikerjakan sebelum pelaksanaan fisik dilakukan dan memerlukan analisis detail dan kompilasi dokumen penawaran dan lainnya. Proses analisis biaya konstruksi adalah suatu proses untuk mengestimasi biaya langsung yang secara umum digunakan sebagai dasar penawaran. Salah satu metode yang digunakan untuk melakukan estimasi biaya konstruksi adalah menghitung secara detail harga satuan pekerjaan berdasarkan nilai indeks atau koefisien untuk analisis biaya bahan dan upah kerja.

Perkiraan biaya memegang peranan penting dalam pelaksanaan proyek. Pada taraf pertama dipergunakan untuk mengetahui berapa besar biaya yang di perlukan untuk pembangunan proyek atau investasi, selanjutnya memiliki fungsi yang samgat luas yaitu merencanakan dan mengendalikan sumber daya seperti material, tenaga kerja, pelayanan maupun waktu.

Untuk meningkatkan efesiensi dan efektifitas kegiatan pembangunan gedung dan bangunan dibidang konstruksi, diperlukan suatu sarana dasar perhitungan harga satuan yaitu Analisa Biaya Konstruksi yang di singkat ABK.

Analisa biaya konstruksi adalah suatu cara perhitungan harga satuan pekerjaan konstruksi, yang dijabarkan dalam perkalian indeks bahan bangunan dan upah kerja dengan bahan bangunan dan standart pengupahan pekrjaan, untuk menyelesaikan persatuan pekerjaan konstruksi. Analisa biaya konstruksi yang selama ini dikenal yaitu analisa biaya berdasarkan BOW. Analisa berdasarkan BOW (Burgerlijke Openbare Werken) ialah suatu ketentuan yang ditetapkan dir. $B O W$ pada zaman pemerintahan belanda.

Namun bila di tinjau dari perkembangan industri konstruksi saat ini, analisa biaya $B O W$ belum memuat pekerjaan beberapa jenis bahan bangunan yang di temukan di pasaran material bangunan dan konstruksi dewasa ini. Disamping itu analisa tersebut hanya dapat digunakan untuk pekerjaan padan karya yang peralatan konvensional. Sedangkan bagi pekerjaan yang menggunakan peralatan modern atau alat berat, analisa biaya $B O W$ yang tidak relevan lagi dengan kebutuhan pembangunan, baik bahan maupun upah tenaga kerja. Namun demikian analisa biaya $B O W$ masih dapat digunakan sebagai pedoman dalam penyusunananggaran biaya. 
Harga Satuan Pokok Kegiatan atau biasa disingkat HSPK adalah harga satuan bahan dan harga upah pekerjaan yang berlaku untuk wilayah pemerintahan kota. Agar tercapainya efesiensi dan efektifitas dalam pelaksanaan anggaran pendapatan belanja daerah kota Lamongan serta sebagai pedoman dalam penyusunan standart harga khususnya yang berkaitan dengan biaya dan harga satuan belanja pada tahun 2005 ditetapkan Keputusan Walikota tentang standart biaya dan harga satuan, dan diperbarui pada tahun 2006. Dalam kondisi perekonomian negara saat ini yang mengalami krisis ekonomi, secara langsung ataupun tidak langsung berdampak pada harga upah pekerja serta harga kebutuhan bahan atau material. Untuk mengatasi permasalahan tersebut, maka diperlukan manajemen yang baik dan teratur pada pelaksanaan pembangunan. Tujuan peneletian kali ini adalah untuk Mengetahui perhitungan estimasi anggaran biaya RAB menggunakan metode SNI dan metode $B O W$.

\section{METODE PENELITIAN}

Perhitungan ini menggunakan metoda SNIdan BOW, yaitu Mengetahui perhitungan estimasi anggaran biaya RAB menggunakan metode SNI dan metode $B O W$. Mengetahui rasio perbandingan hasil harga satuan material, upah dan pekerjaan antara analisa $B O W$ dan SNI.

Untuk mengetahui biaya dan waktu pelaksanaan proyek memerlukan suatu acuan yang berupa data. Data yang dibutuhkan sebagai berikut:

a. Gambar struktur beton

b. Data alat berat;

c. HSPK 2017 Pemerintah Kota Lamongan

\section{Analisa Data}

Pengolahan data dilakukan setelah data- data yang dibutuhkan dalampenelitian ini didapatkan. Langkah-langkah yang dilakukan dalam pengolahan data adalah:

1. Merangkum pekerjaan-pekerjaan yang termasuk dalam pekerjaan struktur beton berdasarkan RAB penawaran kontraktor.

2. Membuat tabel analisis Harga Satuan Pekerjaan (HSP) berdasarkan item pekerjaan.

3. Menghitung Harga Satuan Pokok (HSPK) bahan, tenaga kerja, dan alat. Perhitungan HSPK bahan, tenaga kerja, dan alat mengikuti langkah-langkah yang terdapat dalam pedoman HSPK. Sedangkan kontraktor menggunakan harga satuan yang terdapat pada RAB.

4. Menghitung koefisien HSPK. Koefisien HSPK diperhitungkan dengan menggunakan pedoman HSPK. Sedangkan kontraktor menggunakan koefisien yang terdapat pada RAB.

5. Menghitung HSPK masing-masing pekerjaan struktur beton. Koefisien dikalikan dengan harga satuan untuk mendapatkan jumlah, Setelah itu, masing-masing jumlah akan dikumulatifkan dan dilakukan pembulatan biaya sehingga didapatkan HSPK untuk 
kontraktor dan AHSK.

\section{Perhitungan Volume}

Pada tahap ini, dari data yang diperoleh diolah untuk mencapai tujuan awal Proyek Akhir ini. Pengolahan data ini dengan tahapan sebagai berikut:

a. Menghitung volume item pekerjaan

Tata cara perhitungan volume:

- Perhitungan volume galian tanah

Perhitungan volume galian dengan mengalikan panjang (m), lebar (m), dan tinggi (m) dalam satuan $\mathrm{m} 3$.

$$
\text { Volume }=\text { pxlxt }=m 3
$$

- Perhitungan volume urugan

Perhitungan volume galian dengan mengalikan panjang (m), lebar (m), dan tinggi (m) dalam satuan $\mathrm{m} 3$.

$$
\text { Volume }=p \times l \times t=m 3
$$

- Perhitungan luas bekisting

Perhitungan luas bekisting dengan mengalikan panjang $(\mathrm{m})$ dan lebar $(\mathrm{m})$ dalam satuan $\mathrm{m} 2$.

$$
\text { Volume }=\text { px } l=m 2
$$

- Perhitungan berat pembesian

Perhitungan berat pembesian dengan mengalikan panjang (m), luas (m2), dan berat jenis besi $(\mathrm{kg} / \mathrm{m} 3)$ dalam satuan $\mathrm{kg}$.

$$
\text { Volume }=\text { p } x L \times B J=k g
$$

- Perhitungan Volume beton

Perhitungan volume beton dengan mengalikan panjang (m), lebar (m), tinggi (m) dalam satuan $\mathrm{m} 3$.

$$
\text { Volume }=p \times l \times t=m 3
$$

b. Metode Pelaksanaan

Metode pelaksanaan proyek pembangunan mungkin menggunakan alat berat seperti alat pancang, mobil crane, dan concretepump yang dikerjakan. Material yang digunakan beton dan baja.

c. Produktivitas

Perhitungan produktivitas proyek akhir ini menggunakan acuan HSPK 2013 Pemprov Jatim. Dari hasil perhitungan tersebut akan menghasilkan Rencana Anggaran Biaya dan jadwal dari proyek pembangunan. 


\section{HASIL DAN PEMBAHASAN}

\section{Perhitungan Volume.}

Format daftar volume biasanya telah ditetapkan berupa daftar jenis dan volume pekerjaan (bill of quantity), yang memuat jenis pekerjaan dan volumenya, atau dalam bentuk daftar jenis pekerjaan ((bill of item) yang hanya berisi daftar jenis pekerjaan tanpa volume.

$$
\begin{aligned}
\text { Volume sloof } & =l \times t \times \text { panjang sloof } \\
& =0,4 \times 0,7 \times 40 \\
& =112 \mathrm{~m} 3 \\
\text { Volume kolom } & =p \times l \times t \times \square \text { kolom } \\
& =0,4 \times 0,4 \times 4 \times 16 \\
& =10,24 \mathrm{~m} 3
\end{aligned}
$$

\section{Daftar upah tenaga kerja.}

Daftar Upah Tenaga Kerja pada Proyek Pembangunan Gedung D Fakultas Agama Islam Universitas Islam Lamongan sesuai Upah Tenaga Kerja Kabupaten Lamongan tahun 2017.

Tabel 1 Tabel Upah Tenaga Kerja

\begin{tabular}{|l|l|l|l|}
\hline No. & URAIAN TENAGA & SATUAN & SATUAN HARGA (RP) \\
\hline 1. & Mandor & Org/hari & $95.000,00$ \\
\hline 2. & Kepala Tukang & Org/hari & $90.000,00$ \\
\hline 3. & Tukang & Org/hari & $85.000,00$ \\
\hline 4. & Pekerja & Org/hari & $70.000,00$ \\
\hline 5. & Mekanik & Org/jam & $17.000,00$ \\
\hline 6. & Pembantu Mekanik & Org/jam & $10.500,00$ \\
\hline 7. & Operator Excavator & Org/jam & $17.000,00$ \\
\hline 8. & Operator Wales & Org/jam & $13.500,00$ \\
\hline 9. & Pembantu & Org/jam & $10.500,00$ \\
\hline 10. & Operator Alat Berat & & \\
\hline 11. & Sopir & Org/hari & $80.000,00$ \\
\hline 12. & Pembantu sopir & Org/hari & $70.000,00$ \\
\hline 13. & Penjaga & Org/hari & $75.000,00$ \\
\hline 14 & Buruh terminal & Org/hari & $63.000,00$ \\
\hline 15. & Buruh tidak terampil & Org/hari & $65.000,00$ \\
\hline 16. & Buruh semi teampil & Org/hari & $60.000,00$ \\
\hline 17. & Penjaga alat berat Excavator & Org/mari & $62.500,00$ \\
\hline & & & $63.000,00$ \\
\hline
\end{tabular}


(sumber : Dinas PU Cipta Karya Lamongan 2017)

\section{Data Proyek}

Tahapan penyelenggaraan proyek pembangunan secara menyeluruh dimulai dari perencanaan, perancangan pelaksanaan pembangunan yang harus dikerjakan secara sistematik. Didalam proses ini terdapat unsur yang membentuk ikatan kerjasama dimana masing-masing mempunyai peranan, fungsi dan tanggung jawab yang jelas tujuan yang ingin dicapai adalah efesiensi yang optimal dari tenaga, biaya dan waktu proyek terhadap hasil yang diperoleh.

Data primer yang diperoleh adalah data dokumentasi pelaksanaan pekerjaansaat proyek tersebut berlangsung dan data-data sekunder yang lainya. Berikut adalah data-data yang diperoleh:

- Data upah tenaga kerja tahun 2017

- Data harga bahan bangunan tahun 2017

- Data gambar pekerjaan Proyek pembangunan gedung D Fakultas Agama Islam Lamongan Tabel 2 Rekap Perhitungan Metode SNI

\begin{tabular}{|c|c|c|c|c|c|}
\hline \multirow{2}{*}{ No. } & \multirow{2}{*}{ Uraian Pekerjaan } & \multirow{2}{*}{ Volume } & \multirow{2}{*}{ Sat } & Harga Satuan & \multirow{2}{*}{$\begin{array}{c}\text { Jumlah Harga } \\
\text { Rp. } \\
\end{array}$} \\
\hline & & & & Rp. & \\
\hline $\mathbf{I}$ & PEK. TANAH & & & & \\
\hline 1 & Pekerjaan galian tanah (pile cap) & 132,812 & $\mathrm{~m} 3$ & $24.260,00$ & $3.222 .019,12$ \\
\hline 2 & Pekerjaan Urugan pasir & 18,180 & $\mathrm{~m} 3$ & $273.625,00$ & $4.974 .502,50$ \\
\hline 3 & Pekerjaan galian sloof & 109,38 & $\mathrm{~m} 3$ & $31.800,00$ & $3.478 .125,00$ \\
\hline \multicolumn{5}{|c|}{ Sub Jumlah } & 11.674.646,62 \\
\hline II & PEK. STRUKTUR & & & & \\
\hline $\mathrm{a}$ & Pekerjaan pondasi & & & & \\
\hline 1 & Pekerjaan tiang pancang & 55,200 & $\mathrm{~m} 3$ & $3.857 .249,00$ & $212.920 .144,80$ \\
\hline 2 & pekerjaan pile cap & 154,53 & $\mathrm{~m} 3$ & $1.856 .750,00$ & $286.923 .577,50$ \\
\hline b. & Lantai 1 & & & & \\
\hline 1 & pekerjaan lantai kerja & 15,63 & $\mathrm{~m} 3$ & $1.179 .874,30$ & $18.435 .535,94$ \\
\hline 2 & pekerjaan sloof & 87,50 & $\mathrm{~m} 3$ & $4.336 .780,00$ & $379.468 .250,00$ \\
\hline 3 & pekerjaan kolom & 57,02 & $\mathrm{~m} 3$ & $5.153 .879,00$ & $293.874 .180,58$ \\
\hline 4 & pekerjaan tangga lantai $1-2$ & 4,58 & $\mathrm{~m} 3$ & $4.520 .562,75$ & $20.681 .574,58$ \\
\hline c. & Lantai 2 & & & & \\
\hline 1 & Pekerjaan balok & 52,87 & $\mathrm{~m} 3$ & $4.152 .095,75$ & $219.521 .302,30$ \\
\hline 2 & Pekerjaan pelat lantai & 97,92 & $\mathrm{~m} 3$ & $5.062 .345,00$ & $495.704 .822,40$ \\
\hline 3 & Pekerjan kolom & 57,02 & $\mathrm{~m} 3$ & $5.153 .879,00$ & $293.874 .180,58$ \\
\hline \multirow{3}{*}{\multicolumn{5}{|c|}{ Sub Jumlah }} & 2.242.085.143,26 \\
\hline & & & & & $2.253 .759 .789,88$ \\
\hline & & & & & $2.253 .760 .000,00$ \\
\hline
\end{tabular}

Terbilang :

Dua Milyar Seratus Dua Ratus Lima Puluh Tiga Juta Tujuh Ratus Enam Ribu Rupiah 
Tabel 3 Rekap Perhitungan Metode BOW

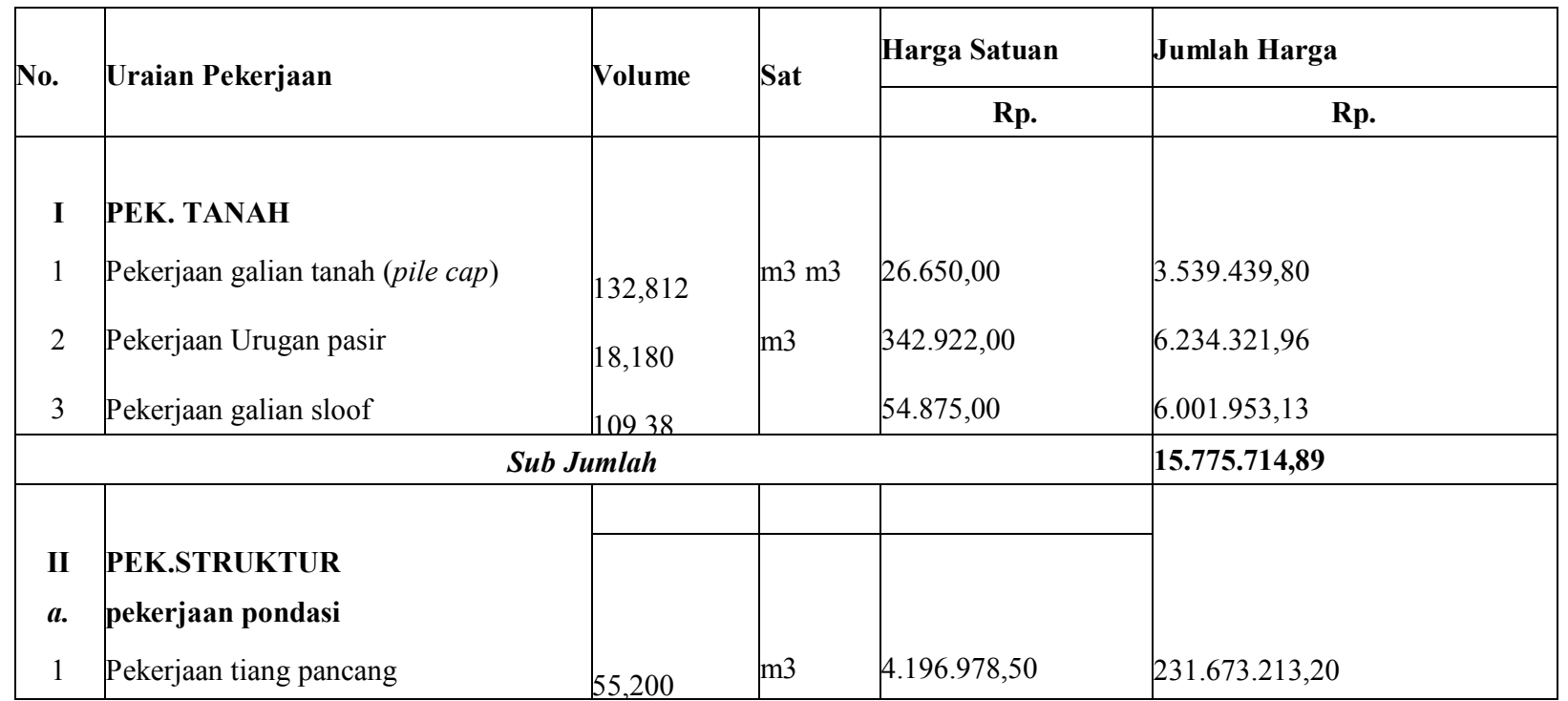

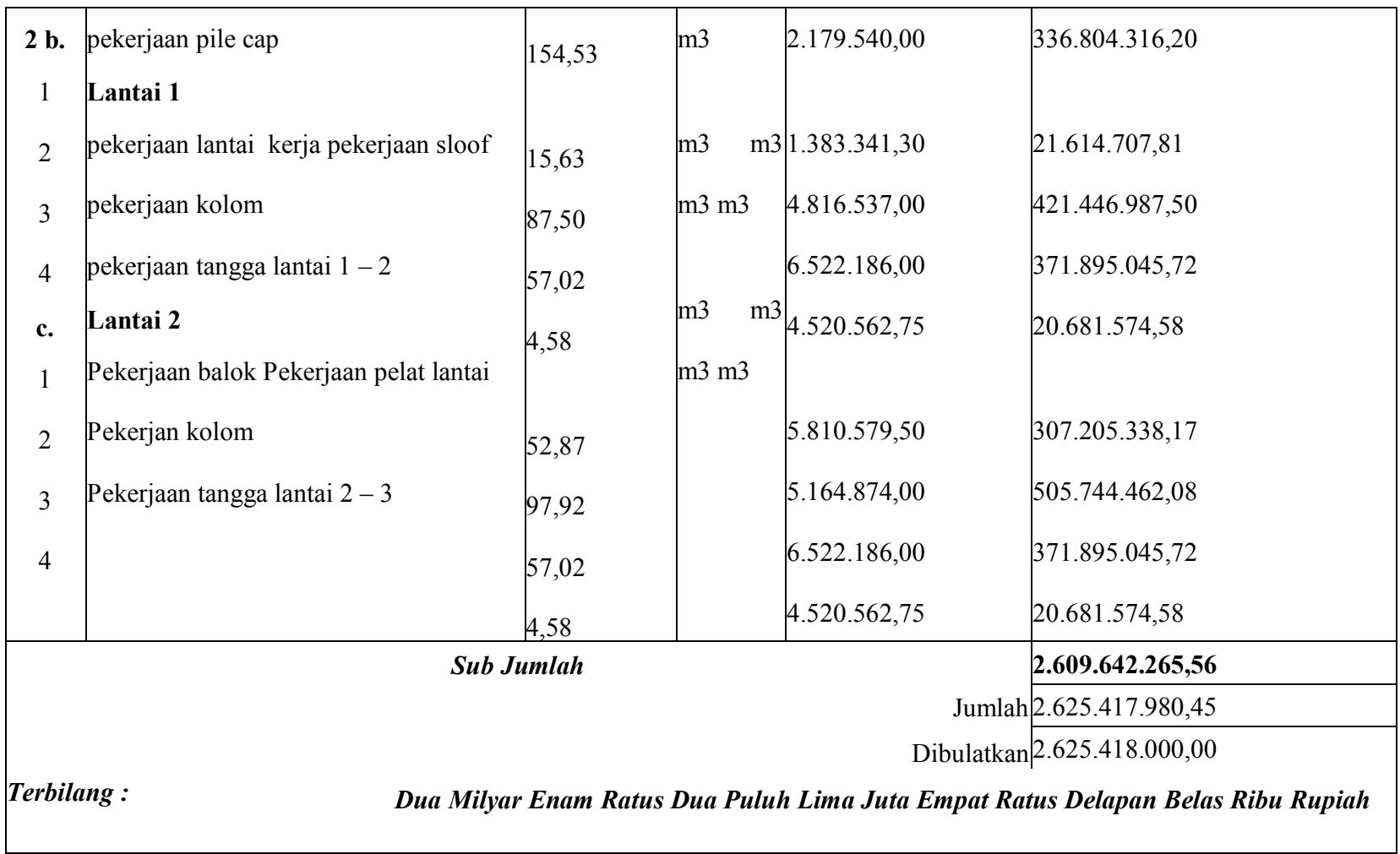


Tabel 4 Bobot Pekerjaan Metode SNI

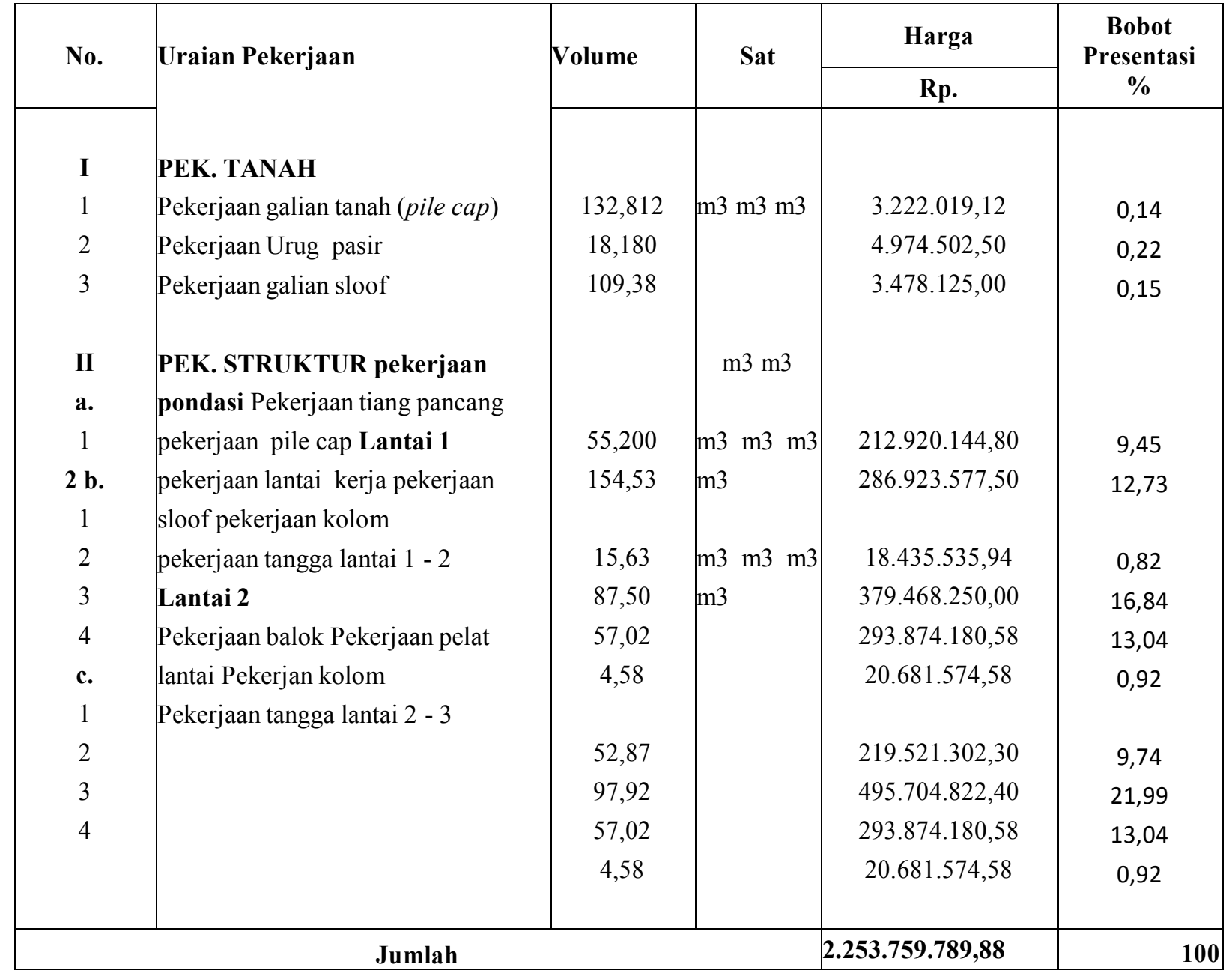


Tabel 5 Bobot Pekerjaan metode BOW

\begin{tabular}{|c|l|c|c|c|c|}
\hline \multirow{2}{*}{ No. } & Uraian Pekerjaan & Volume & Sat & Harga & Bobot \\
Presentasi \%
\end{tabular}

\section{KESIMPULAN dan SARAN}

\section{Kesimpulan}

Dari rekapitulasi perhitungan antara BOW dan SNI yang telah dilakukan maka diperoleh hasil perhitungan seperti di bawah ini.

\begin{tabular}{|c|c|c|c|}
\hline No & $\begin{array}{c}\text { Uraian } \\
\text { Pekerjaan }\end{array}$ & Harga SNI & Harga BOW \\
\hline 1. & $\begin{array}{c}\text { Pekerjaan } \\
\text { Tanah }\end{array}$ & $11.674 .646,62$ & $15.775 .714,89$ \\
\hline 2. & $\begin{array}{c}\text { Pekerjaan } \\
\text { Pondasi }\end{array}$ & $400.220 .622,88$ & $451.675 .320,79$ \\
\hline 3. & $\begin{array}{c}\text { Pekerjaan } \\
\text { Struktur }\end{array}$ & $1.720 .949 .570,41$ & $2.019 .872 .885,61$ \\
\hline I & Total & $2.253 .759 .789,88$ & $2.625 .417 .980,45$ \\
\hline II & Dibulatkan & $2.253 .760 .000,00$ & $2.625 .418 .000,00$ \\
\hline
\end{tabular}

Dari perhitungan diatas anggaran biaya yang ekonomis adalah menggunakan metode SNI. Metode SNI mempunyai anggaran biaya lebih ekonomis yaitu sebesar Rp 2.253.760.000,00 
dibandingkan dengan metode BOW yang sebesar Rp. 2.625.418.000,00. Hal ini terjadi karena koefesiensi metode SNI lebih rendah di bandingkan BOW.

\section{Saran}

Di dalam perhitungan harga satuan pekerjaan sebaiknya dilakukan dengan teliti, khususnya pemilihan metode perhitungan yang tepat sehingga didapatkan anggaran biaya yang ekonomis serta dapat dipertanggung jawabkan. Dengan kekurungan metode BOW maka disarankan agar metode BOW tidak dipakai lagi untuk menghitung RAB kerena tidak lagi relevan sesuai perkembangan industri konstruksi saat ini sehingga kedepanya dalam menghitung RAB proyek hanya menggunakan metode SNI dengan pertimbangan efesiensi dan efektifitas kerja.

\section{Daftar Pustaka}

[1] Adam. (2013). Basic Architecture. http:// Civilengineering2021.blogspot.com/

[2] Afiako, M. Aulia Rohman. (2016), yang berjudul Analisa Estimasi Anggaran Biaya Pada Proyek Rehabilitasi Kantaor UPT Pemadam Kebakaran Kabupaten Lamongan Menurut Analisa SNI dan Metode BOW, Universitas Islam Lamongan.

[3] Arafuru.com/sipil/apa-itu-struktur-dan- konstruksi-bangunan.html

[4] Callahan, Mat. (1992). Metode penjadwalan konstruksi

[5] Dian, Arietadi. (2008). Teknik Kontruksi Bangunan. Jakarta : Direktorat Jenderal Manajemen Pendidikan Dasar dan Menengah, Departemen Pendidikan Nasional, 2008.

[6] Fatena, Susy. (2002). Alat Berat untuk Proyek Konstruksi.Jakarta: PT. Rineka Cipta.

[7] Husen, Abrar. (2011). Manajemen Proyek. Yogyakarta : Elib.unicom

[8] Indonesia Forum. Bebas (2013). Tiang Pancang. http:www.forumbebas.com/thread.143579

[9] Perkejaan, Tim Umum. (2017). Harga Satuan Pokok Kerja(HSPK) 2017.

[10] Surabaya: Dinas Pekerjaan Umum. Proyek sipil.blogspot.co.id/2013/06/cara-menghitungvolume-beton-kolom.html?m=1Purba, Radiks (2006:209), Tentetive set of Broad Acounting Principles Enterplise, http://dokumen.tips

[11] studi analisis harga satuan pekerja pada konstruksi bangunan dengan metode html (diunduh pada 28 juli 2017)

[12] https://www.slideshare.net/mobile/MiraPemayun/struktur-beton-bertulang(diunduh pada 28 juli 2017)

[13] www.besibeton.net/tabel-berat-besi-beton- polos-SNI/html (diunduh pada 24 juli 2017)

[14] www.hdesignideas.com/2012/01/menghitung- volume-besi-perm3-beton.html/ (diunduh pada 24 juli 2017)

[15] www.ilmusipil.com/tabel-berat-besi.html (diunduh pada 24 juli 2017)

[16] www.struktur-rumah.com/p/menghitung- kebutuhan-bekisting.html? $m=1$ (diunduh pada 24 juli 2017) 